\title{
Low-Resistivity p-Type Doping in Wurtzite ZnS Using Codoping Method
}

\author{
Deng-Feng Li, Min Luo, Bo-Lin Li, Cheng-Bing Wu, Bo Deng, and Hui-Ning Dong \\ Department of Mathematics and Physics, Chongqing University of Posts and Telecommunications, Chongqing 400065, China \\ Correspondence should be addressed to Deng-Feng Li; phyldf@gmail.com
}

Received 31 May 2013; Accepted 24 July 2013

Academic Editor: Haiyan Xiao

Copyright (C) 2013 Deng-Feng Li et al. This is an open access article distributed under the Creative Commons Attribution License, which permits unrestricted use, distribution, and reproduction in any medium, provided the original work is properly cited.

\begin{abstract}
By using first principles calculations, we propose a codoping method of using acceptors and donors simultaneously to realize lowresistivity and high carrier concentration p-type $\mathrm{ZnS}$ with wurtzite structure. The ionization energy of single $\mathrm{N}_{\mathrm{S}}$ can be lowered by introducing the $\mathrm{III}_{\mathrm{Zn}}-\mathrm{N}_{\mathrm{S}}(\mathrm{III}=\mathrm{Al}, \mathrm{Ga}$, In) passivation system. Codoping method in $\mathrm{ZnS}(2 \mathrm{~N}$, III) has lower formation energy comparing with single doping of $\mathrm{N}$ since III elements act as reactive codopants.
\end{abstract}

\section{Introduction}

Wide bandgap semiconductors, such as $\mathrm{ZnX}(\mathrm{X}=\mathrm{O}, \mathrm{S}, \mathrm{Se})$, have attracted attention due to their potential application in short-wavelength light-emitting devices. Unfortunately, the doping unipolarity, that is, it can be doped either $\mathrm{p}$-type or $\mathrm{n}$ type, but not both, impedes the implementation of the materials [1]. Earlier researches show that $\mathrm{ZnS}$ and $\mathrm{ZnO}$ are difficult to be doped as p-type due to asymmetric doping limitation [1-3]. In order to obtain low-resistivity p-type ZnS, single doping and codoping methods are studied. Nakamura et al. fabricate Li-doped $\mathrm{ZnS}$ by a low-pressure metal organic chemical vapor deposition technique [2]. They find that it is p-type conductivity, and the acceptor ionization energy is about $196 \mathrm{meV}$, which is larger than the calculated results of $155 \mathrm{meV}$ by Gai et al. [3]. Gai et al. calculated ionization energies for possible single doping method to obtain p-type $\mathrm{ZnS}$ [3]. The result shows that $\mathrm{N}$-doped $\mathrm{ZnS}$ is promised to be p-type, but the ionization energy is calculated to be $144 \mathrm{meV}$, which is still deep acceptor level.

In recent years, codoping method was suggested to solve the unipolarity of semiconductor $[1,4,5]$. P-type doping in $\mathrm{ZnO}$ is realized by codoping with $\mathrm{N}$ acceptors and $\mathrm{Ga}$ donors in the ratio of $\mathrm{N}: \mathrm{Ga}=2: 1[6,7]$. For p-type $\mathrm{ZnS}$, experimental researches realize it by codoping with $\mathrm{N}$ and $\mathrm{Li}$ dual acceptors, and the hole concentration is measured to be $10^{18} \mathrm{~cm}^{-3}$ [8]. Theoretical investigations show that the codoping method of acceptor-donor-acceptor is more efficient than the single-doping method. They realize p-type $\mathrm{ZnS}$ by codoping with $\mathrm{N}$ acceptors and In or Al donors based on first principles calculations [9-11]. Codoping method makes the acceptor levels broaden and delocalize compared with the single doping of $\mathrm{N}$. In addition, p-type $\mathrm{ZnS}$ nanocrystals can be obtained by codoping with $\mathrm{N}$ and $\mathrm{Ga}$, In, or $\mathrm{Al}$ [12]. However, earlier researches about p-type $\mathrm{ZnS}$ with codoping method mainly focus on the density of state analysis. Quantifiable parameters, such as acceptor ionization energy and formation energy, are not presented. In addition, they have studied the zinc blende (ZB) ZnS. P-type ZnS with wurtzite (WZ) structure has not been investigated up to now. Therefore, the purpose of this study is to investigate p-type $\mathrm{ZnS}$ with $\mathrm{WZ}$ structure by codoping with $\mathrm{N}$ and $\mathrm{Ga}, \mathrm{Al}$, and In. Acceptor ionization energy, formation energy, and density of states are presented to analyze the effects of $\mathrm{Ga}, \mathrm{Al}$, and In codopant on p-type ZnS.

\section{Calculation Method}

We performed the calculations using the projector augmented wave method [13] within the generalization gradient approximation (GGA) [14], as implemented in the Vienna $a b$ initio simulation (VASP) code [15]. $3 d$ and $4 s$ electrons of $\mathrm{Zn}$ are treated as valence electrons. The energy cutoff for the plane wave expansion sets with a $450 \mathrm{eV}$. For the Brillouin zone integration, we use Monkhorst-Pack special 
$k$-points [16], equivalent to the $2 \times 2 \times 2$ mesh. Wurtzite supercells containing 96 atoms are used. For charged defect systems, a uniform background charge is added to maintain the global charge neutrality of the periodic system. All the geometries are allowed to relax until the Hellmann-Feynman force becomes less than $0.02 \mathrm{eV} / \AA$. The optimized lattice constants for $\mathrm{ZnS}$ is $a=b=3.85 \AA, c=6.29 \AA$, which are in good agreement with the experimental values $a=b=3.81 \AA$, $c=6.23 \AA$.

The ionization energy of an acceptor with respect to VBM is calculated as follows $[1,17]$ :

$$
\begin{aligned}
\varepsilon(0 /-)= & {\left[E(\alpha,-)-\left(E(\alpha, 0)+\varepsilon_{D}^{k}(0)\right)\right] } \\
& +\left[\varepsilon_{D}^{\Gamma}(0)-\varepsilon_{\mathrm{VBM}}^{\Gamma}(\mathrm{ZnS})\right],
\end{aligned}
$$

where $\varepsilon_{D}^{k}$ and $\varepsilon_{D}^{\Gamma}$ are the defect levels at the special $k$-points (averaged by weights) and at $\Gamma$-point, respectively; $E(\alpha,-)$ or $E(\alpha, 0)$ is the total energy of the supercell at charge state -1 or neutral for defect $\alpha ; \varepsilon_{\mathrm{VBM}}^{\Gamma}$ is the VBM energy of the host $\mathrm{ZnS}$ at $\Gamma$-point.

The formation energy of an isolated impurity $\alpha$ in charge state $q$ is described as follows $[1,17]$ :

$$
\Delta H_{f}(\alpha, q)=\Delta E(\alpha, q)+n_{\mathrm{Zn}} \mu_{\mathrm{Zn}}+n_{\mathrm{S}} \mu_{\mathrm{S}}+n_{\mathrm{A}} \mu_{\mathrm{A}}+q E_{f},
$$

where $\Delta E(\alpha, q)=E(\alpha, q)-E(\mathrm{ZnS})+n_{\mathrm{Zn}} E(\mathrm{Zn})+n_{\mathrm{S}} E(\mathrm{~S})+$ $n_{\mathrm{A}} E(\mathrm{~A})+q \varepsilon_{\mathrm{VBM}}$. The $n_{i}(i=\mathrm{Zn}, \mathrm{S}$, and $\mathrm{A})$ are the numbers of exchanged particles between the supercell, $q$ is the defect charge state, $\mu_{i}$ is the chemical potential of constituent $i$ referenced to elemental solid/gas with energy $E_{i} \cdot \mu_{\mathrm{Zn}}$ and $\mu_{\mathrm{S}}$ in (2) are not independent but limited by the formation of stable $\mathrm{ZnS}$ compound, $\mu_{\mathrm{Zn}}+\mu_{\mathrm{S}}=\Delta H_{f}(\mathrm{ZnS})$, where $\Delta H_{f}(\mathrm{ZnS})$ is the formation enthalpy of solid $\mathrm{ZnS}$.

\section{Results and Discussion}

We firstly determine the most stable structure of codoped $\mathrm{ZnS}$ with $\mathrm{N}$ and group III elements (Al, Ga, and In) based on minimizing the total energy. For $\mathrm{ZnS}$ (N, III), we discuss two possible configurations. One configuration is $\mathrm{N}_{\mathrm{S}}-\mathrm{III}_{\mathrm{Zn}}$ pair occupied the nearest-neighbor sites and the other is a pair separated certain distance away. The result shows that the formation of the first case is energetically favorable. When another $\mathrm{N}$ atom is doped in the $\mathrm{ZnS}$ (N, III), total energy calculations show that the $\mathrm{N}$ atom also prefers to locate at the nearest-neighbor site, as shown in Figure 1. For the stable $\mathrm{ZnS}$ ( $2 \mathrm{~N}, \mathrm{III})$, the bond length of $\mathrm{N}-\mathrm{Al}, \mathrm{N}-\mathrm{Ga}$, and $\mathrm{N}-\mathrm{In}$ is $1.9 \AA$, $2.0 \AA$, and $2.2 \AA$, respectively, which is remarkably smaller than $\mathrm{Zn}-\mathrm{S}$ bond length of pristine $\mathrm{ZnS}$ of $2.36 \AA$.

The calculated acceptor ionization energy and formation energy of codoping with $\mathrm{N}$ and III elements in $\mathrm{ZnS}$ are presented in Table 1. The acceptor ionization energy denotes the provided hole in $\mathrm{ZnS}$, and the formation energy controls the dopant solubility, which is important for p-type doping of semiconductor. When only $\mathrm{N}$ atom is doped in $\mathrm{ZnS}$, the ionization energy is $103.9 \mathrm{meV}$, which is smaller than that of $\mathrm{N}$ doping in $\mathrm{ZB} \mathrm{ZnS}(144 \mathrm{meV})$. This suggests that $\mathrm{N}$ doping generates a deep acceptor level above the valence band.

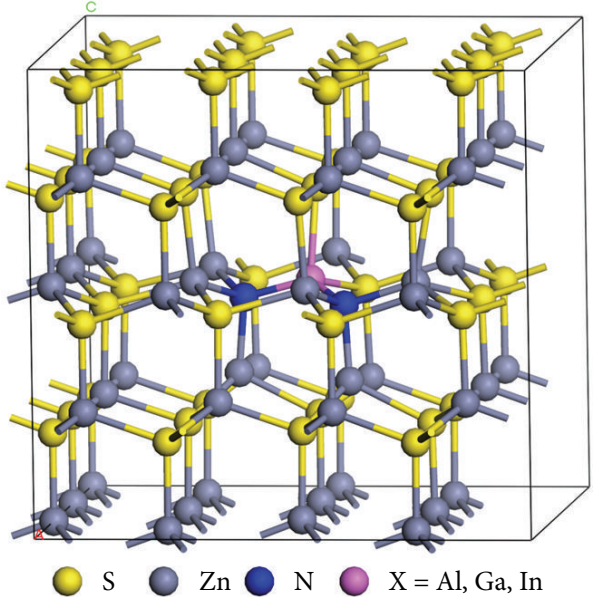

Figure 1: Schematic structure of codoping with $\mathrm{N}$ and $\mathrm{X}$ (Al, Ga, and In) in wurtzite $\mathrm{ZnS}$.

$\mathrm{CBM}$ CBM

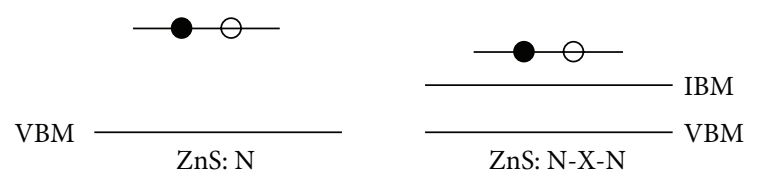

FIGURE 2: Schematic illustration of the energy level for single doping of $\mathrm{N}$ and codoping with $\mathrm{N}$ and $\mathrm{X}(\mathrm{Al}, \mathrm{Ga}$, and $\mathrm{In})$ in $\mathrm{ZnS}$.

Fortunately, codoping with $\mathrm{N}$ and III elements in $\mathrm{ZnS}$ can remarkably reduce the ionization energy. Shallow acceptor level exists in $\mathrm{ZnS}$, and the acceptor ionization energies of $\mathrm{Al}_{\mathrm{Zn}}-2 \mathrm{~N}_{\mathrm{S}}$ and $\mathrm{Ga}_{\mathrm{Zn}}-2 \mathrm{~N}_{\mathrm{S}}$ pairs are $40.1 \mathrm{meV}$ and $37.5 \mathrm{meV}$, respectively. The lower ionization energy of codoping with $\mathrm{N}$ and III elements can be explained by Figure 2. ZnS (N, III) creates a fully unoccupied impurity band above the VBM. The $\mathrm{N}$ atom passivates the III elements to form the $\mathrm{ZnS}$ (N, III) passivated system. When excess $\mathrm{N}$ atoms are available, the impurity band is regarded as new VBM, and $\varepsilon_{\mathrm{VBM}}^{\Gamma}(\mathrm{ZnS})$ in (1) is replaced by the impurity band minimum (IBM). The acceptor transition occurs between the $\mathrm{N}$ energy level and the IBM rather than the original VBM. Thus, the ionization energy can be remarkably reduced.

The formation energies of $2 \mathrm{~N}_{\mathrm{S}}-\mathrm{III}_{\mathrm{Zn}}$ complex and single doping of $\mathrm{N}$ for $\mathrm{ZnS}$ in neutral charge state and at $\mu_{i}=0$ in (2) are also shown in Table 1 . The low formation energy suggests this defect has high carrier concentration. Our calculations reveal that the formation energy of $2 \mathrm{~N}_{\mathrm{S}}-\mathrm{III}_{\mathrm{Zn}}$ complex is smaller than that of single doping of $\mathrm{N}$. This can be explained by the density of states (DOS) analysis. Figure 3 shows DOS of $\mathrm{N}$-p state in $\mathrm{ZnS}(2 \mathrm{~N}, \mathrm{Al})$ and $\mathrm{ZnS}(\mathrm{N})$. The DOS of the $\mathrm{N}$ atom in $\mathrm{ZnS}(2 \mathrm{~N}, \mathrm{Al})$ is similar to that in $\mathrm{ZnS}(2 \mathrm{~N}, \mathrm{Ga})$ and $\mathrm{ZnS}$ (2N, In), and we only present the representative result 


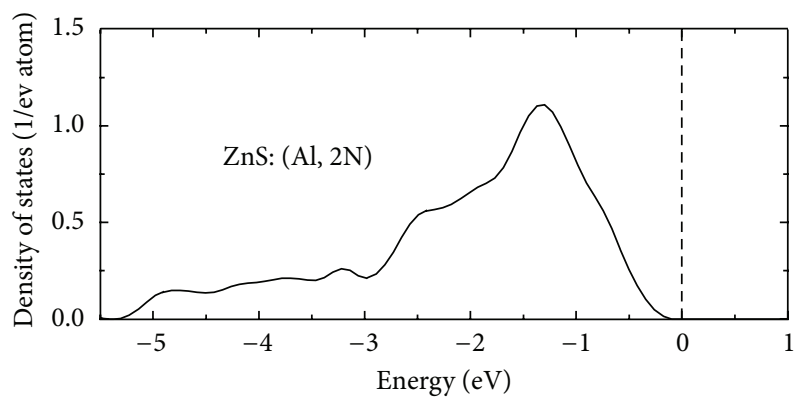

(a)

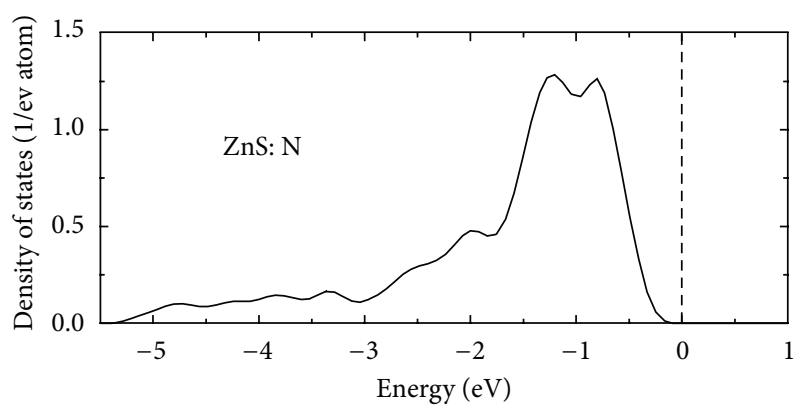

(b)

Figure 3: DOS of N-p states for (a) ZnS codoped with $\mathrm{Al}$ and $2 \mathrm{~N}$ species and (b) ZnS doped with the $\mathrm{N}$ atom.

TABLE 1: Ionization energy $\varepsilon(0 /-)$ and formation energy $\Delta H_{f}$ of defect complexes in $\mathrm{ZnS}$.

\begin{tabular}{lcccc}
\hline & $2 \mathrm{~N}_{\mathrm{S}}-\mathrm{Al}_{\mathrm{Zn}}$ & $2 \mathrm{~N}_{\mathrm{S}}-\mathrm{Ga}_{\mathrm{Zn}}$ & $2 \mathrm{~N}_{\mathrm{S}}-\mathrm{In}_{\mathrm{Zn}}$ & $\mathrm{N}_{\mathrm{S}}$ \\
\hline$\varepsilon(0 /-)(\mathrm{meV})$ & 40.1 & 37.5 & 44.1 & 103.9 \\
$\Delta H_{f}(\mathrm{eV})$ & 3.04 & 3.17 & 3.16 & 3.35 \\
\hline
\end{tabular}

of $\mathrm{ZnS}(2 \mathrm{~N}, \mathrm{Al})$. We observe that a narrow band forms near $\mathrm{VBM}$ in $\mathrm{ZnS}(\mathrm{N})$ due to the large electronegativity of $\mathrm{N}$ comparing with that of S. The localization of DOS for $\mathrm{N}$ atom results in high formation energy. Meanwhile, the $\mathrm{N}$-impurity bandwidth in $\mathrm{ZnS}(2 \mathrm{~N}, \mathrm{Al})$ is increased due to the interaction of N-p and Al-p orbitals, which indicates that the defect is easily formed. Therefore, we can see that the codoping using $\mathrm{N}$ as an acceptor and III elements ( $\mathrm{Al}, \mathrm{Ga}$, and $\mathrm{In})$ as reactivecodopant donor is very effective for materials design to obtain low-resistivity and high-concentration p-type $\mathrm{ZnS}$.

\section{Conclusion}

In summary, our first principles calculations reveal that the codoping method with two acceptors and one donor is effective to realize low-resistivity and high carrier concentration p-type $\mathrm{ZnS}$ with $\mathrm{WZ}$ structure. The ionization energy of single $\mathrm{N}_{\mathrm{S}}$ can be lowered by introducing the $\mathrm{III}_{\mathrm{Zn}}-\mathrm{N}_{\mathrm{S}}$ passivation system due to the acceptor transition between the $\mathrm{N}$ level and the IBM rather than the VBM. The codoping method in $\mathrm{ZnS}$ (2N, III) has lower formation energy compared with single doping of $\mathrm{N}$ since III elements act as reactive codopants with $\mathrm{N}$.

\section{Acknowledgment}

The authors acknowledge financial support from the Key Program of the Natural Science Foundation of Chongqing (cstc2012jjB50010).

\section{References}

[1] S.-H. Wei, "Overcoming the doping bottleneck in semiconductors," Computational Materials Science, vol. 30, no. 3-4, pp. 337348, 2004.

[2] S. Nakamura, J. Yamaguchi, S. Takagimoto, Y. Yamada, and T. Taguchi, "Luminescence properties of lithium-doped ZnS epitaxial layers grown by MOCVD," Journal of Crystal Growth, vol. 237-239, no. 1-4, pp. 1570-1574, 2002.

[3] Y. Gai, J. Li, B. Yao, and J.-B. Xia, “The bipolar doping of ZnS via native defects and external dopants," Journal of Applied Physics, vol. 105, no. 11, Article ID 113704, 2009.

[4] Y. Yan, J. Li, S.-H. Wei, and M. M. Al-Jassim, "Possible approach to overcome the doping asymmetry in wideband gap semiconductors," Physical Review Letters, vol. 98, no. 13, Article ID 135506, 2007.

[5] O. K. Echendu, A. R. Weerasinghe, D. G. Diso, F. Fauzi, and I. M. Dharmadasa, "Characterization of n-Type and p-Type ZnS Thin Layers Grown by an Electrochemical Method," Journal of Electronic Materials, vol. 42, no. 4, pp. 692-700, 2013.

[6] Y. Gai, J. Li, S.-S. Li, J.-B. Xia, Y. Yan, and S.-H. Wei, “Design of shallow acceptors in $\mathrm{ZnO}$ through compensated donoracceptor complexes: a density functional calculation," Physical Review B, vol. 80, no. 15, Article ID 153201, 2009.

[7] M. Kumar, T.-H. Kim, S.-S. Kim, and B.-T. Lee, "Growth of epitaxial p-type $\mathrm{ZnO}$ thin films by codoping of $\mathrm{Ga}$ and $\mathrm{N}$," Applied Physics Letters, vol. 89, no. 11, Article ID 112103, 2006.

[8] L. Svob, C. Thiandoume, A. Lusson, M. Bouanani, Y. Marfaing, and $\mathrm{O}$. Gorochov, "p-type doping with $\mathrm{N}$ and $\mathrm{Li}$ acceptors of $\mathrm{ZnS}$ grown by metalorganic vapor phase epitaxy," Applied Physics Letters, vol. 76, no. 13, pp. 1695-1697, 2000.

[9] T. Yamamoto, S. Kishimoto, and S. Iida, "Control of valence states for ZnS by triple-codoping method," Physica B, vol. 308310, pp. 916-919, 2001.

[10] T. Yamamoto, S. Kishimoto, and S. Iida, "Materials design for p-type ZnS with blue Ag emission by triple-codoping method," Physica Status Solidi, vol. 229, no. 1, pp. 371-375, 2002.

[11] S.-Z. Li, J.-C. Liu, X.-D. Yang, and D.-Q. Jiang, "First-principles study of $\mathrm{Al}, \mathrm{N}$ codoped p-type ZnS," Chinese Journal of High Pressure Physics, vol. 25, no. 6, pp. 519-525, 2011.

[12] X. Ma, "Study of the P-type doping properties of $\mathrm{ZnS}$ nanocrystals," Journal of Nanomaterials, vol. 2011, Article ID 952616, 5 pages, 2011.

[13] G. Kresse and D. Joubert, "From ultrasoft pseudopotentials to the projector augmented-wave method," Physical Review B, vol. 59, no. 3, pp. 1758-1775, 1999.

[14] J. P. Perdew and W. Yue, "Accurate and simple density functional for the electronic exchange energy: generalized gradient approximation," Physical Review B, vol. 33, no. 12, pp. 8800$8802,1986$.

[15] G. Kresse and J. Furthmüller, "Efficiency of ab-initio total energy calculations for metals and semiconductors using a plane-wave basis set," Computational Materials Science, vol. 6, no. 1, pp. 15-50, 1996. 
[16] J. D. Pack and H. J. Monkhorst, "Special points for Brillouinzone integrations," Physical Review B, vol. 13, no. 12, pp. 51885192, 1976.

[17] Y. Yan and S.-H. Wei, "Doping asymmetry in wide-bandgap semiconductors: origins and solutions," Physica Status Solidi, vol. 245, no. 4, pp. 641-652, 2008. 

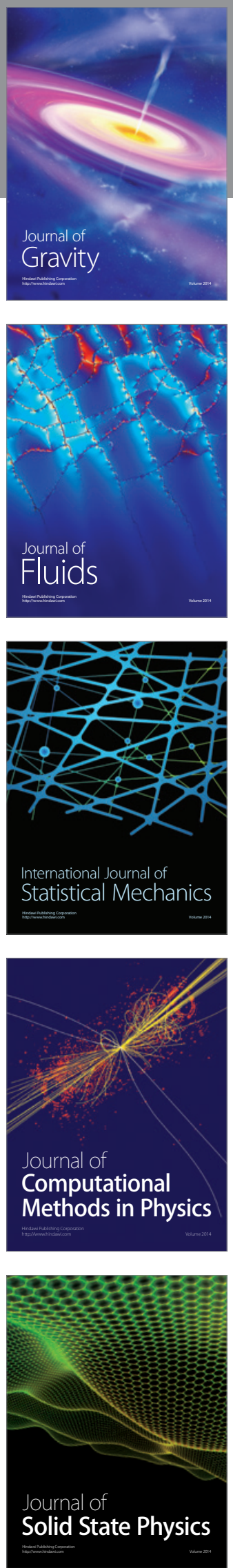

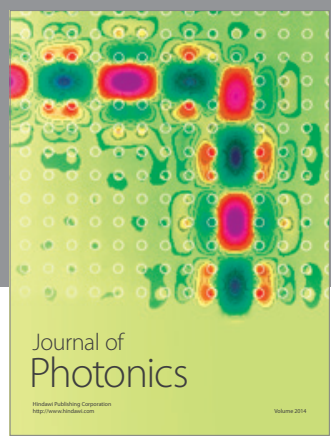

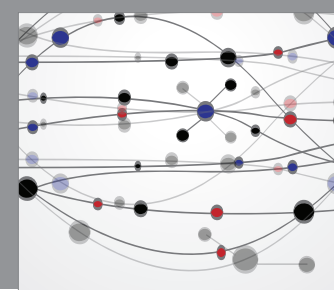

The Scientific World Journal

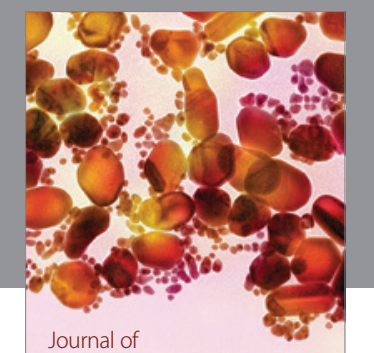

Soft Matter
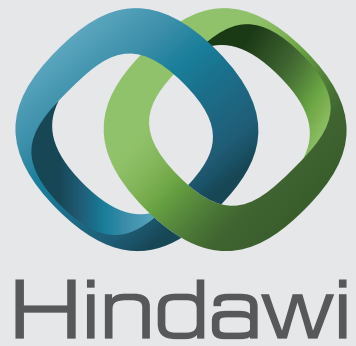

Submit your manuscripts at

http://www.hindawi.com
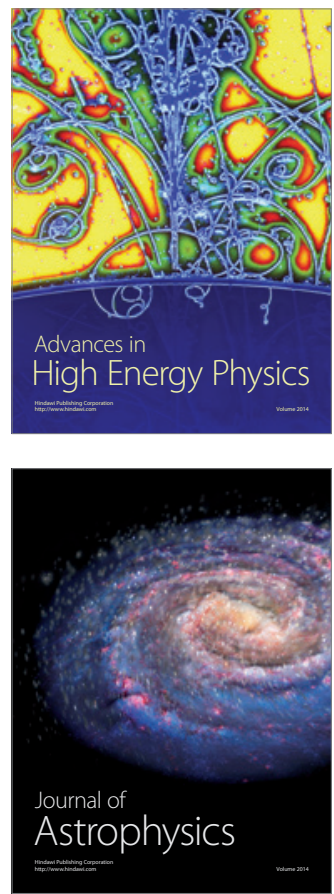
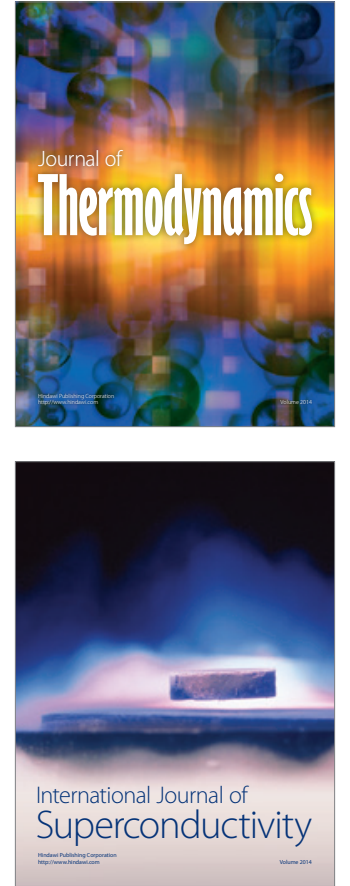
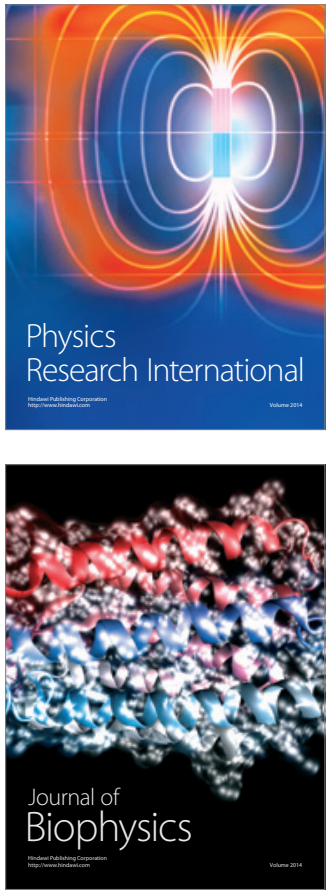
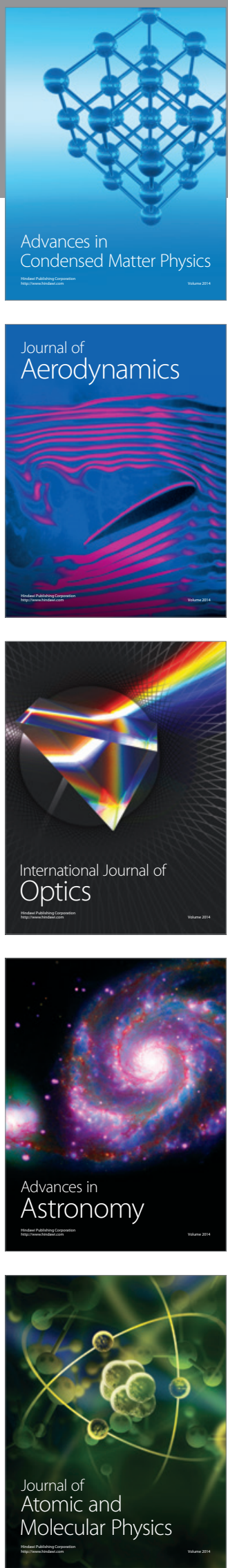